\title{
Dielectrical and structural characterization of iron oxide added to hydroxyapatite
}

\author{
C C SILVA*, F P FILHO, M F P GRAÇA, M A VALENTE and A S B SOMBRA \\ Physics Department, Aveiro University, Aveiro, Portugal
}

MS received 10 July 2007; revised 19 May 2008

\begin{abstract}
In this work we report preparation, structural and dielectric analyses of iron oxide added in hydroxyapatite bioceramic $\left(\mathrm{Ca}_{10}\left(\mathrm{PO}_{4}\right)_{6}(\mathrm{OH})_{2}-\mathrm{HAP}\right)$. Hydroxyapatite is the main mineral constituent of teeth and bones with excellent biocompatibility with hard and muscle tissues. The samples were prepared through a calcination procedure associated with dry high-energy ball milling process with different iron concentrations $(1,2.5$ and $5 \mathrm{wt} \%)$. The dielectric analyses were made measuring the sample impedance in the frequency range $1 \mathrm{kHz}-10 \mathrm{MHz}$, at room temperature. The relative permittivity of the ceramics, at $10 \mathrm{MHz}$, are between $7.13 \pm 0.07(1 \mathrm{wt} \%)$ and $6.20 \pm 0.11(5 \mathrm{wt} \%)$ while $e^{\prime \prime}$ are between $0.0795 \pm 0.008(1 \mathrm{wt} \%)$ and $0.067 \pm 0.012$ $(5 \mathrm{wt} \%)$. These characteristics were related to the sample microstructures studied by X-ray diffraction and SEM.
\end{abstract}

Keywords. Hydroxyapatite; dielectrical analysis; iron oxide.

\section{Introduction}

It is difficult to imagine the present medicine without the possibility of reconstruction of parts of the human body with implants (Vogel and Höland 1987; Hench 1993; Pajamäki et al 1995). The first materials used for implants frequently caused inflammations and rejections. For the use in medicine the materials must not have a significant influence in the metabolism. Several materials and composites are used in the production of prosthesis, for example, metallic alloys, metallic materials with hydroxyapatite film, alumina and polyethylene (Zeng and Lancefield 2000). The hydroxyapatite (HAP) is used in orthopedics surgeries (Sugimoto et al 1996) and odontological for wadding or surfaces covering, this despite its weak mechanical properties (Weeber and Bakker 1988). To improve the mechanical properties of hydroxyapatite several studies present the substitution of calcium, in the HAP structure, by metals (Elliot 1994) or ions as for instance, silicon and magnesium (Kim et al 2003), lead (Xiu et al 2004), titanium and zirconium (Silva et al 2004) and alumina (Viswanath and Ravishankar 2006). The presence of iron in the apatite structure seems to be important because iron is a vital element in the circulatory system and is essential for the functioning of numerous proteins in cells (Morrissey et al 2005). Biomaterials with iron have a very important role in medicine, for example, ferrimagnetics bioglass ceramics (FBC) was introduced for hyperthermic treatment of bone cancer (Kokubo et al 1992; Leventouri et al 2005). They are

*Author for correspondence (ccsilva@ua.pt) complex, multiphase, biocompatible and bioactive materials, motivating us to dope the hydroxyapatite with that metal. The main aim of this work is to determine how iron oxide is introduced into the apatite structure. Structural, optical, electrical, dielectric and magnetic measurements will be done to characterize such bioceramics.

This paper reports the preliminary results of the relative permittivity behaviour vs structure modifications, due to the addition of iron oxide to hydroxyapatite. The dielectric properties of HAP are of interest because electromagnetic fields have been shown to accelerate healing in bone fractures. In addition, an interest in the dielectric properties of HAP stems from the suggestion that electrically insulating HAP coatings might be used on implantable devices (Timothy and Eldon 2002; Silva et al 2005).

\section{Experimental}

The HAP crystalline powders were prepared by a highenergy dry milling, for $20 \mathrm{~h}$. The chemical equation (1) represents the expected chemical reaction:

$$
6 \mathrm{CaHPO}_{4}+4 \mathrm{Ca}(\mathrm{OH})_{2} \rightarrow \mathrm{Ca}_{10}\left(\mathrm{PO}_{4}\right)_{6}(\mathrm{OH})_{2}+6 \mathrm{H}_{2} \mathrm{O} .
$$

For the reaction, the starting materials $\left(\mathrm{CaHPO}_{4}\right.$ and $\left.\mathrm{Ca}(\mathrm{OH})_{2}\right)$, with stoichiometric proportionality for $10 \mathrm{~g}$ of total powder, were placed in a stainless steel vessel inside a Fritsch Pulverisette 6 planetary mill system. The ratio between powders and ball mass was near $1 / 6$. The reaction was performed using $370 \mathrm{rpm}$ for $20 \mathrm{~h}$ in air. To avoid excessive heat the milling was performed in $60 \mathrm{~min}$ milling steps with 10 min pauses. 
Different weight percentages of iron oxide $\left(\mathrm{Fe}_{2} \mathrm{O}_{3}\right)(1$, 2.5 and $5 \%$ ) were added to the obtained powder. After this the obtained HAP with iron oxide powder added were submitted to a calcination process at $1150^{\circ} \mathrm{C}$ for $24 \mathrm{~h}$ with a heating rate of $4^{\circ} \mathrm{C} / \mathrm{min}$.

The X-ray diffraction (XRD) patterns were obtained at room temperature using powder samples in an X'Pert MPD Philips diffractometer (with $\mathrm{K}_{\alpha}$ radiation, $\lambda=$ $1.54056 \AA$ ) at $40 \mathrm{kV}$ and $30 \mathrm{~mA}$. Intensity data were collected by the step counting method (step $0.02^{\circ}$ and a time per step of $1 \mathrm{~s})$ between 20 and $60^{\circ}(2 \theta)$. The output data obtained from Rietveld (1967) refinement was used to calculate the crystallite size. The analysis of the crystallite size $\left(L_{\mathrm{c}}\right)$ of the HAP and $\mathrm{Ca}_{2} \mathrm{Fe}_{2} \mathrm{O}_{5}$ phases has been done for all samples using the Scherrer's equation (Azároff 1968):

$$
L_{c}=\frac{k \lambda}{\beta \cos \theta},
$$

where $k$ is the shape coefficient $(k=1$ was chosen, considering that the shape of this point is spherical), $\lambda$ the wavelength, $\beta$ the full width at half maximum (FWHM) of the peak of each phase and $\theta$ the diffraction angle. For this purpose, we chose the single peak near 25.8 ( $2 \theta$ degree) within the pattern and according to $P 6_{3} / m$ space group of HAP whose peak corresponds to $h k l=002$ and 33.4 ( $2 \theta$ degree) within the pattern and according to Pnma space group of $\mathrm{Ca}_{2} \mathrm{Fe}_{2} \mathrm{O}_{5}$. This peak corresponded to $h k l=141$, both along the $c$ crystallographic axis. We have used the $\mathrm{LaB}_{6}$ (SRM 660 - National Institute of Standard Technology) powder standard pattern to determine the instrumental width $\left(w_{\text {inst }}=0.087^{\circ}\right)$ and afterwards to calculate the crystallite size via (2). The $\beta$ parameter has to be corrected using the following equation:

$$
\beta=\sqrt{w_{\text {exp }}^{2}-w_{\text {inst }}^{2}},
$$

where $w_{\text {exp }}$ and $w_{\text {inst }}$ are the experimental and instrumental width, respectively. $w_{\text {inst }}$ was obtained from $\mathrm{LaB}_{6}$ powder standard pattern using the following expression:

$$
w_{\text {inst }}=\sqrt{\operatorname{Utg}^{2} \theta+\operatorname{Vtg} \theta+W},
$$

where $U, V$ and $W$ were obtained from the output file extracted from Rietveld refinement parameters of $\mathrm{LaB}_{6}$ samples (Rietveld 1967). The morphological analysis of the sample structure was performed using the scanning electron microscopy (SEM), Philips XL-30, operating with bunches of primary electrons ranging from 12 to $20 \mathrm{keV}$.

For the dielectric measurements, the samples were prepared from the powders as discs of $1.2 \times 10^{-2} \mathrm{~m}$ diameter for all samples, with an average thickness of $1.85 \mathrm{~mm}$ for $5 \mathrm{wt} \%, 2.39 \mathrm{~mm}$ for $2.5 \mathrm{wt} \%$ and $3.23 \mathrm{~mm}$ for $1 \mathrm{wt} \%$. The pellets were sintered at $900^{\circ} \mathrm{C}$ for $5 \mathrm{~h}$ with the purpose of achieving a compact sample. The electrodes were formed by painting with silver paste (Joint Metal-PC200) on the opposite sides of the samples.

The dielectric data was carried out with a HP 4291A Material Impedance Analyzer in conjunction with a HP 4194 Impedance Analyzer, which jointly covered the frequency region from $1 \mathrm{kHz}$ to $40 \mathrm{MHz}$, at room temperature $(300 \mathrm{~K})$, measuring the sample capacitance and dielectric loss.

\section{Results and discussion}

Figure 1 presents the XRD pattern of the reaction of hydroxyapatite added with iron oxide at different weight

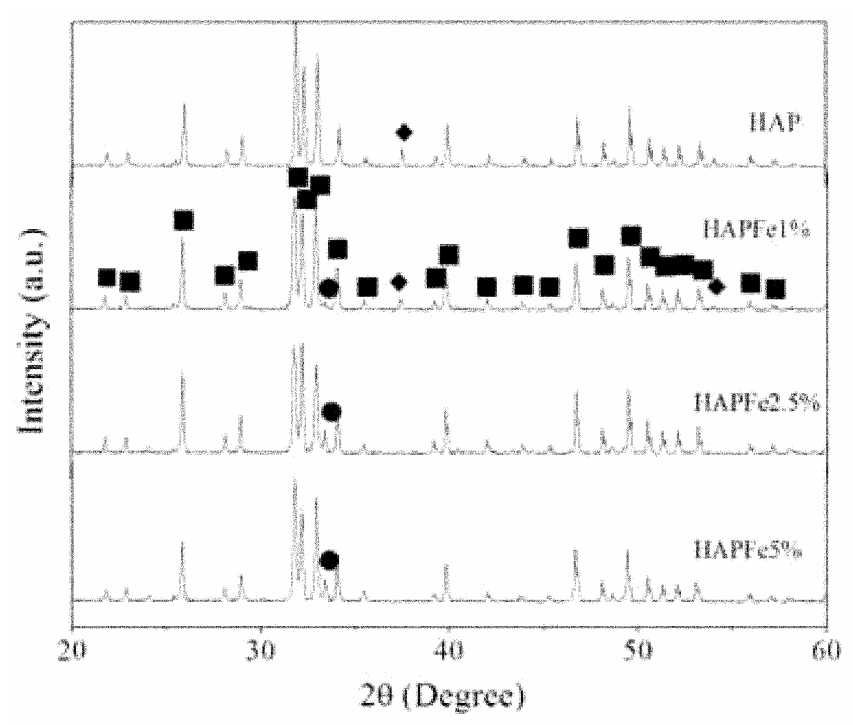

Figure 1. XRD patterns of the HAP, $\mathrm{HAPFe} 1 \%, \mathrm{HAPFe} \cdot 5 \%$ and $\mathrm{HAPFe} 5 \%$ samples. $\mathrm{HAP}(\mathbf{\square}), \mathrm{Ca}_{2} \mathrm{Fe}_{2} \mathrm{O}_{5}(\mathbf{\bullet})$ and $\mathrm{CaO}(\bullet$ (JCPDS-Pattern 74-0566, 47-1744 and 77-2376).

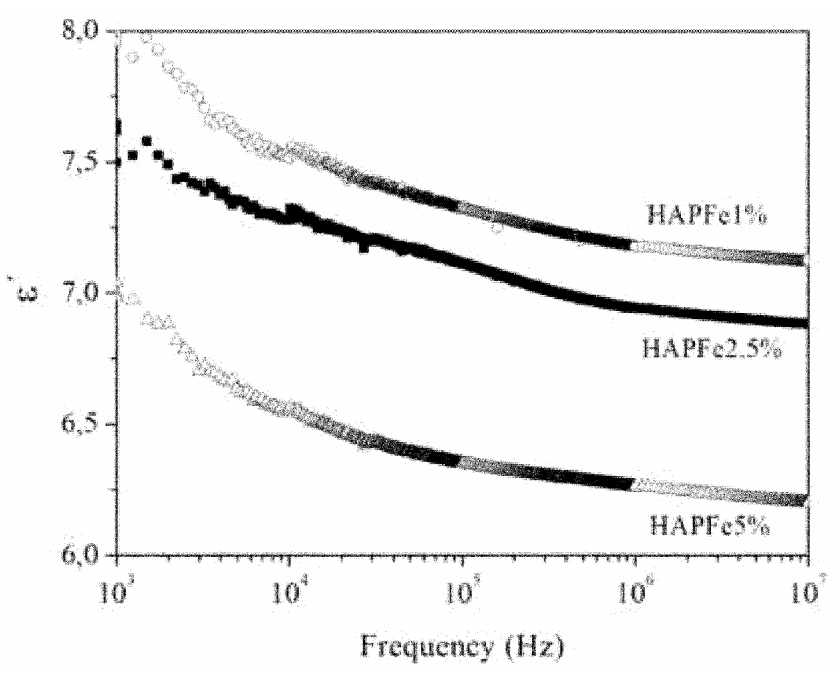

Figure 2. $\varepsilon^{\prime}$ vs frequency at $300 \mathrm{~K}$ for all the samples. 
Table 1. Measure of the relative permittivity for the samples at $10 \mathrm{MHz}(300 \mathrm{~K})$ and crystalline size $\left[\mathrm{HAP}(\mu \mathrm{m})\right.$ and $\left.\mathrm{Ca}_{2} \mathrm{Fe}_{2} \mathrm{O}_{5}(\mathrm{~nm})\right]$.

\begin{tabular}{lcccc}
\hline Sample & HAPFe $\%$ & HAPFe $\% 5 \%$ & HAPFe5\% & HAP [19-20] \\
\hline$\varepsilon^{\prime}$ & $7 \cdot 13 \pm 0.07$ & $6.88 \pm 0.09$ & $6.20 \pm 0.11$ & 11.09 \\
$\varepsilon^{\prime \prime}$ & $0.0795 \pm 0.0008$ & $0.0819 \pm 0.0011$ & $0.0670 \pm 0.0012$ & - \\
$\mathrm{Ca}_{2} \mathrm{Fe}_{2} \mathrm{O}_{5}(\mathrm{~nm})$ & $49.9 \pm 3 \cdot 2$ & $67.5 \pm 5.6$ & $95.9 \pm 9.5$ & - \\
$\mathrm{HAP}(\mu \mathrm{m})$ & $0.20 \pm 0.014$ & $0.77 \pm 0.018$ & $0.81 \pm 0.018$ & $0.02 \pm 0.54$ \\
\hline
\end{tabular}

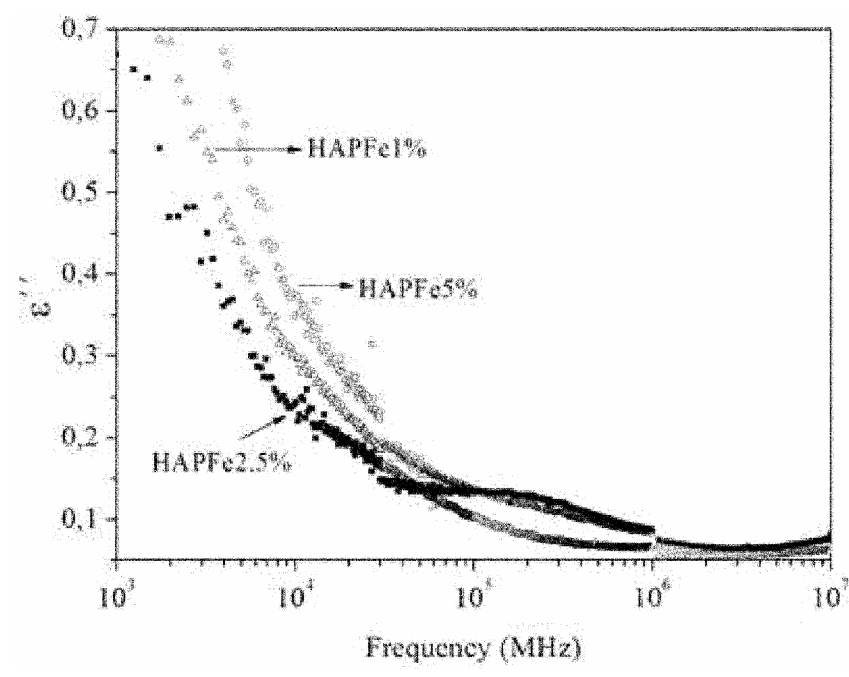

Figure 3. $\varepsilon^{\prime \prime}$ vs frequency at $300 \mathrm{~K}$ for all the samples.

percentages $(1,2 \cdot 5$ and $5 \%)$. It is identified as the hydroxyapatite phase (JCPDS) and iron brownmillerite $\left(\mathrm{Ca}_{2} \mathrm{Fe}_{2} \mathrm{O}_{5}\right)$ (JCPDS) in all samples. The formation of the brownmillerite indicates that the added iron oxide was inserted into the $\mathrm{Ca}_{2} \mathrm{Fe}_{2} \mathrm{O}_{5}$ phase. This phase increases with iron concentration showing calcium-iron interaction. Other identified phase was $\mathrm{CaO}$, formed through the dissociation of the $\mathrm{Ca}(\mathrm{OH})_{2}$ (JCPDS) during the calcination process. This phase is present in the HAP before the addition of the iron oxide (figure 1) and it disappears in the $2.5 \%$ wt sample.

The relative permittivity $\left(\varepsilon^{\prime}\right)$ vs frequency (figure 2) decreases with the rise of the concentration of iron oxide and with increasing frequency for all the studied samples (table 1).

Figure 3 shows the frequency dependence of $\varepsilon^{\prime \prime}$, out of phase parts of the dielectric permittivity. In the graph of figure 3 the value of frequency starts at $10^{3} \mathrm{~Hz}$ because at lower frequencies the scattering of $\varepsilon^{\prime \prime}$ values is very large. At $10 \mathrm{MHz}$, the $\varepsilon^{\prime \prime}$ values are between $0.0795 \pm 0.0008$ ( $1 \mathrm{wt} \%$ ) and $0.067 \pm 0.0012$ ( $5 \mathrm{wt} \%$ ), and also decrease softly with the rise of the added iron oxide concentration to hydroxyapatite (figure 3 and table 1). A similar behaviour was observed in all other measured frequencies. The values obtained at $10 \mathrm{MHz}$ for the $\varepsilon^{\prime}$ and $\varepsilon^{\prime \prime}$ are shown in table 1 .

Analysing the $\varepsilon^{*}$ frequency dependence (figures 2 and 3 ), it suggests that in this frequency range these samples do not have relaxation mechanisms.

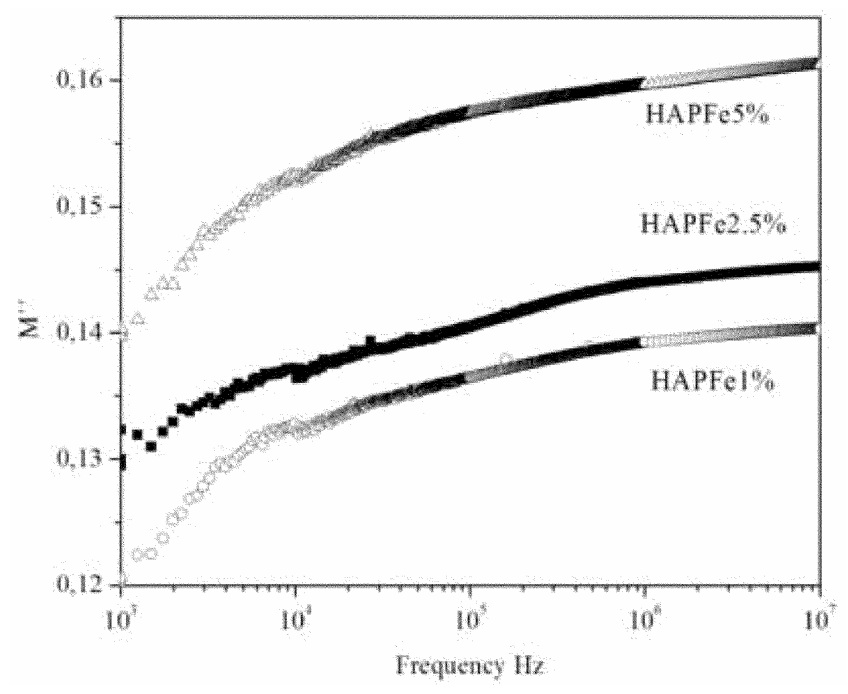

Figure 4. $M^{\prime \prime}$ vs frequency at $300 \mathrm{~K}$ for all the samples.

Figure 4 shows the frequency dependence of the imaginary part of $M^{*}\left(M^{*}=\left(\varepsilon^{*}\right)^{-1}=1 /\left(\varepsilon^{\prime}-j \varepsilon^{\prime \prime}\right)\right.$ (Silva et al 2005)). This formalism, which minimizes the electro sample interface capacitance contribution at low frequencies, emphasizes small features at low frequencies, revealing that these samples do not present relaxation mechanisms in this frequency range.

From the XRD pattern analysis (2), it was observed that the samples HAPFe $1 \%$, HAPFe $2.5 \%$ and HAPFe $5 \%$ have $\mathrm{Ca}_{2} \mathrm{Fe}_{2} \mathrm{O}_{5}$ crystallites with sizes of $\sim 49.9 \pm 3 \cdot 2$, $67.5 \pm 5.6$ and $95.9 \pm 9.5 \mathrm{~nm}$ (table 1), respectively and hydroxyapatite (HAP) crystallites with $\sim 0.20 \pm 0.014$, $0.77 \pm 0.018$ and $0.81 \pm 0.018 \mu \mathrm{m}$ (table 1$)$.

The SEM micrographs show particles having larger dimensions than those calculated by XRD (figures 5a and b) suggesting the existence of agglomerates of crystallites. Nevertheless, both XRD and SEM results reveal that the crystallites and particle sizes increase with the rise of the iron oxide concentration. The undoped hydroxyapatite, in the ceramic form, presents a $\varepsilon^{\prime} \sim 11.09$ (table 1) with crystallite size of $\sim 20.63 \pm 0.54 \mathrm{~nm}$ (Silva et al 2005, 2006). The HAP-Fe microscopic results (figure 5) show images with a strong variation of the microstructure with iron oxide concentration. Spherical particles dispersed in the form of grain duplex (figure 5a) are observed through back scattering electron (BSE) method in the sample with the lowest percentage of added iron oxide (1\%) assigned to 

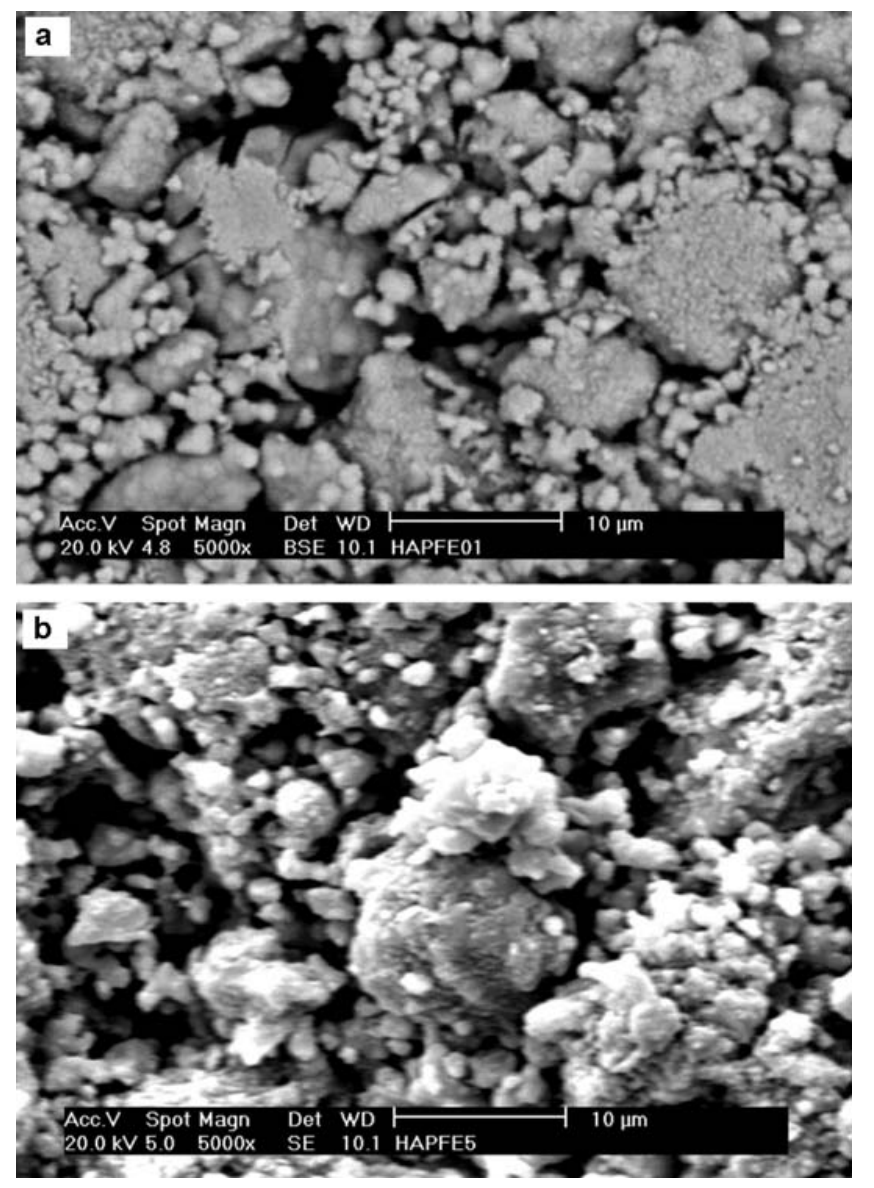

Figure 5. SEM micrographs of the sample: a. HAP-Fe $1 \%$ with 5000X and b. HAP-Fe 5\% with 5000X.

a long time of calcinations and sinterization. Thus, the increase of the crystalline size of HAP phase should lead to a more uniform microstructure (figure 5).

By comparing the dielectric results of these samples with those of the bare HAP, it is observed that the incorporation of iron oxide in the brownmillerite $\left(\mathrm{Ca}_{2} \mathrm{Fe}_{2} \mathrm{O}_{5}\right)$ phase and the increase of the crystallites sizes of HAP and $\left(\mathrm{Ca}_{2} \mathrm{Fe}_{2} \mathrm{O}_{5}\right)$, due by the calcination and sinterization time are the main effects responsible for the observed decrease of $\varepsilon^{\prime}$ and $\varepsilon^{\prime \prime}$ (table 1).

\section{Conclusions}

$\mathrm{Ca}_{2} \mathrm{Fe}_{2} \mathrm{O}_{5}$ (brownmillerite) phase was obtained with the addition of iron oxide to hydroxyapatite samples. The formation of the brownmillerite indicates that the iron oxide has reacted with the HAP during the sintering process. This phase increases with the iron concentration showing calcium-iron interaction. The real part of the relative permittivity $\left(\varepsilon^{\prime}\right)$ and the out of phase part of the relative permittivity $\left(\varepsilon^{\prime \prime}\right)$, decrease from the sample with $1 \%$ of iron oxide to the sample with $5 \%$. The decrease of the $\varepsilon^{\prime}$ can be ascribed to the rise of crystalline size of HAP phase and to the $\mathrm{Ca}_{2} \mathrm{Fe}_{2} \mathrm{O}_{5}$ phase. The particles size of $\mathrm{HAP}$ and $\mathrm{Ca}_{2} \mathrm{Fe}_{2} \mathrm{O}_{5}$ phases in the sintered samples increases with the rise of $\mathrm{Fe}_{2} \mathrm{O}_{3}$ concentration.

\section{Acknowledgements}

The authors thank the Physics Department (I3N), Aveiro University, LOCEM (Physics Department, Federal University of Ceará, Brazil) for the use of their laboratories for samples preparation and Fundação para a Ciência e Tecnologia (FCT) for financial support (SFRH/BPD/ 26715/2006).

\section{References}

Azároff L V 1968 Elements of X-ray crystallography (McGrawHill Book Company)

Elliott J C 1994 Structure and chemistry of the apatites and other calcium orthophosphates, in Studies in inorganic chemistry (Amsterdam, The Netherlands: Elsevier Science and Technology) 18 p. 137

Hench L L 1993 Introduction, in An introduction to bioceramics (eds) L L Hench and J Wilson (New Jersey, USA: World Scientific) 1 pp 1-24

Ikenaga M, Ohura H, Nakamura T, Kotoura Y, Yamamuro T, Oka M, Ebisawa Y and Kokubo T 1991 Bioceramics 4255

JCPDS-Pattern 74-0566 (HAP-REF), 47-1744 $\left(\mathrm{Ca}_{2} \mathrm{Fe}_{2} \mathrm{O}_{5}\right)$, 77$2376(\mathrm{CaO})$

Kim S R, Lee J H, Kim Y T, Riu D H, Jung S J, Lee Y J, Chung S C and Kim Y H 2003 Biomaterials 241389

Kokubo T, Ebisawa Y, Sugimoto Y, Kihiama M, Ohura K, Yamamuro T, Hiraoka M and Abe M 1992 Bioceramics 5213

Leventouri Th, Kis A C, Thompson J R and Anderson I M 2005 Biomaterials 264924

Morrissey R, Rodríguez-Lorenzo L M and Gross K A $2005 \mathrm{~J}$. Mater. Sci.: Mater. Med. 16387

Ohura K, Ikenaga M, Takashi N, Yakao Y, Yukihiro E, Tadashi K, Yoshihiro K and Masanori O 1991 J. Appl. Biomater. 2153

Pajamäki K J J , Lindholm T S, Andersson Ö H, Karlsson K H, Vedel E, Yli-Urpo A and Happonen R P 1995 J. Mater. Sci.: Mater. Med. 614

Rietveld H M 1967 Acta Crystallogr. 22151

Silva C C, Valente M A, Graça M P F and Sombra A S B 2004 Solid State Sci. 61365

Silva C C, Valente M A, Graça M P F and Sombra A S B 2005 Non-crystalline Solids 3512945

Silva C C, Valente M A, Graça M P F and Sombra A S B 2006 Non-crystalline Solids $\mathbf{3 5 2} 1490$

Sugimoto T, Dirige G E and Maramatsu A 1996 J. Colloid \& Interf. Sci. 182444

Timothy P H and Eldon D C 2002 J. Biomed. Mater. Res. Part A 60643

Viswanath B and Ravishankar N 2006 Scr. Mater. 55863

Vogel W and Höland W 1987 Angew. Chem. Int. 26527

Weeber A W and Bakker H 1988 Physica B153 93

Xiu Z, Mengkai L, Feng G, Shufen W, Dong X and Duorong Y 2004 Inorg. Chem. Commun. 7604

Zeng H and Lancefield W R 2000 Biomaterials 2123 